\title{
Do Paradigma Essencialista para O Pós-Estruturalismo: Uma Reflexão Epistemológica Sobre Sexualidade
}

\author{
Tânia Pinafi ${ }^{1}$ \\ Psicóloga e Mestre em Psicologia pela Universidade Estadual Paulista-UNESP, \\ Assis, SP, Brasil
}

\begin{abstract}
Resumo
Neste trabalho buscamos apresentar uma reflexão epistemológica em termos de circunstâncias históricas, psicológicas e sociológicas sobre a normalização da sexualidade a partir de um modelo antitético - normal versus abjeto. Igualmente, nos interessa explorar as contribuições do pensamento queer sobre os modos de pensar a sexualidade. Neste sentido nosso foco recai, por um lado, sobre como um modelo epistemológico erigido sob um sujeito dado de antemão nas ciências humanas veio a se constituir em uma das formas de legitimação da discriminação sexo/gênero e, por outro, sobre a busca de formulações teóricas que coloquem em tela a naturalidade com que marcamos certas existências como abjetas para, assim, incitar um pensamento de combate à homofobia prevalecente em nossa sociedade. Em última instância, o que está em voga é um debate em torno à quais pressupostos teóricos utilizar para melhor compreender a capacidade performativa dos sujeitos que vivem fora das fronteiras da heterossexualidade. Pois, agora, como antes, a psicologia não pode ser refratária aos acontecimentos sociais, devendo considerar os sujeitos não apenas em face de sua interioridade como também perante as relações sociais, históricas e culturais do ambiente que os circunda.
\end{abstract}

Palavras-chave: Epistemologia, sexualidade, queer.

\section{From the Esencialist Paradigm to Post- Structuralism: An Epistemological Analysis Regarding Sexuality}

\begin{abstract}
In this paper, we seek to develop an epistemological analysis of the normalization of sexuality based on an antithetical model- normal vs. abject, in terms of historical, psychological and sociological circumstances. Furthermore, we are interested in exploring the contributions of queer theory in relation to the thinking of sexuality. Keeping this in mind, our focus lies on two main areas. First, on an epistemological model based upon the universal subjects in human sciences that defined certain kind of sex/gender discrimination. Secondly, we search for theoretical formulations that expose the natural form in which we label certain existences as abject, and through this, try to construct a way of fighting existing homophobia in our society. Finally, the key aspect of the current discussion relies in the theoretical knowledges that can be used to better comprehend the performative capacity of subjects that live beyond the boundaries of heterosexuality. Taking this into account, now as in the past, psychology cannot ignore social events, having to consider not only the interiority of subjects, but also the social, historical and cultural environments that surround their lives.
\end{abstract}

Keywords: Epistemology, sexuality, queer.

Endereço para correspondência: Calle Moldes, 2277, Piso 3, Departamento “E”, Belgrano, Ciudad Autónoma de Buenos Aires, Argentina 1428. E-mail: tania.pinafi@gmail.com

Agência de financiamento: Conselho Nacional de Desenvolvimento Científico e Tecnológico (CNPq). 


\section{De lo Paradigma Esencialista para el Post-Estructuralismo: Una Reflexión Epistemológica sobre Sexualidad}

\section{Resumen}

En este trabajo buscamos presentar una reflexión epistemológica en términos de circunstancias históricas, psicológicas y sociológicas sobre la normalización de la sexualidad a partir de un modelo antitético - normal versus abyecto. Igualmente, nos interesa explorar las contribuciones del pensamiento queer sobre los modos de pensar la sexualidad. En este sentido nuestro foco recae, por un lado, sobre un modelo epistemológico erigido bajo un sujeto dado de antemano en las ciencias humanas que se constituyó en una de las formas de legitimación de la discriminación sexo/género y, por otro, sobre la búsqueda de formulaciones teóricas que pongan en tela la naturalidad con que marcamos determinadas existencias como abyectas para, así, incitar un pensamiento de combate a la homofobia prevaleciente en nuestra sociedad. En última instancia, lo que está en boga es un debate en torno a cuales presupuestos teóricos utilizar para mejor comprender la capacidad performativa de los sujetos que viven fuera de las fronteras de la heterosexualidad. Pues, ahora, como antes, la psicología no puede ser refractaria a los acontecimientos sociales, debiendo considerar a los sujetos no solamente frente a su interioridad sino también ante las relaciones sociales, históricas y culturales del ambiente que los circunda.

Palabras clave: Epistemología, sexualidad, queer.

Minayo (2001, p. 12) diz que: "A história da ciência revela não um 'a priori', mas o que foi produzido em determinado momento histórico com toda a relatividade do processo de conhecimento". Esta asserção traz consigo implicações biopolíticas ${ }^{2}$ importantes que serão sopesadas à luz das contribuições do pensamento queer sobre os modos de pensar a sexualidade. E, dito isto, é importante destacar que o desenvolvimento de diferentes teorias sobre a sexualidade nada mais é que o resultado da confrontação de novas formas de conceber o mundo e, portanto, a divisão da sexualidade em homo e hetero diz respeito a uma determinada condição epistemológica da ciência sobre as condições de produção do processo de conhecimento em relação à sexualidade. Além disso, vale destacar que os objetos de estudo de uma determinada disciplina podem sofrer alterações à medida que as teorias científicas vão se desenvolvendo. Desta forma, nos

2 Por biopolítica se entende a maneira pela qual se racionalizaram, a partir do século XVIII, certos problemas inerentes à prática governamental em relação ao tema da população, a saber: saúde, higiene, natalidade, longevidade e raça. Desse modo, a biopolítica alude à questão da multiplicidade de corpos, ou seja, a população. interessa apresentar uma reflexão epistemológica em termos de circunstâncias históricas, psicológicas e sociológicas sobre a normalização ${ }^{3}$ da sexualidade a partir de um modelo antitético - normal versus abjeto.

Se bem é certo que há uma ampla produção científica em relação à patologização das sexualidades, todavia há muito por fazer no que concerne a entender a capacidade performativa dos sujeitos que vivem fora das fronteiras da heterossexualidade. Porém, antes de enveredarmos por esta seara precisamos percorrer um pouco da história que organizou a construção da sexologia sob o signo da patologia.

O processo de produção de sujeitos patologizados tem entre suas heranças a visão naturalista que imperou até o final do século XVIII. O legado da ideologia naturalista, que fundamenta

O conceito de normalização aqui utilizado está em consonância com a concepção de Michel Foucault (2008, p. 75), para quem: “A normalização disciplinar consiste em primeiro colocar um modelo, um modelo ótimo que é construído em função de certo resultado, e a operação de normalização disciplinar consiste em procurar tornar as pessoas, os gestos, os atos, conformes a esse modelo, sendo normal precisamente quem é capaz de se conformar a essa norma e o anormal quem não é capaz." 
a existência de binarismos, - onde o primeiro termo é sempre superior ao segundo: homem/mulher, heterossexual/homossexual, etc - repousa sobre a ideia de que existe uma complementaridade entre os sexos, bem como a correspondência de papéis sociais adequados a cada um deles.

De fato, as sociedades, em sua maioria, estão organizadas sob modelos dicotômicos em torno à sexualidade que remetem, por sua vez, a gêneros também dicotômicos. De tal modo, a eleição de um parceiro(a) sexual (homem ou mulher), se diferente, de seu sexo biológico, logo, heterossexual; se igual, homossexual. Desta forma, o império das dicotomias traz como resultado a essencialização ${ }^{4}$ das identidades sexuais, pois, se não for heterossexual; será seu oposto.

Em síntese, pode-se dizer que para a corrente essencialista o sexo e a sexualidade repousam sob uma base conceitual biológica, enquanto que para a perspectiva pós-estruturalista o gênero e a identidade sexual são interpretações sociais estruturadas a partir desta base biológica. Todavia, nem o sexo biológico e nem a sexualidade estão, conceitualmente, livres de influências culturais.

$\mathrm{Na}$ atualidade a heterossexualidade ainda figura como a sexualidade socialmente estimulada, ocupando um lugar central na construção da subjetividade. No entanto, a primazia da heterossexualidade não tem nada de natural, podendo ser mapeada através do dispositivo da sexualidade tal como foi concebido por Michel Foucault (1988).

Este dispositivo, ancorado em procedimentos de poder-saber ao qual Foucault (1988) denominou scientia sexualis, ordenou uma tecnologia política do sexo que regulou a sexualidade em função de alguns elementos vinculados as práticas sexuais.

Ao se classificar as condutas sexuais em base a um modelo antitético (normal versus abjeto) a racionalidade científica do paradigma médico-legal e higienista do século XIX codificou um corpus de proposições disciplinares que patolo-

4 A essencialização é o processo de categorização social que pela via da naturalização passa a designar atributos imutáveis para categorizar aos entes aos quais se aplica. gizou as relações afetivo-sexuais entre pessoas do mesmo sexo ao longo do século XIX ao XX.

Um dos efeitos regulatórios sobre o sexo foi a emergência e visibilização, como nunca antes vista, das "sexualidades periféricas" (o louco, os sodomitas, a criança, a mulher histérica etc.) e o aparecimento de uma infinidade de classificações patologizantes a partir do referencial da "sexualidade regular", ou seja, heterossexual, reprodutiva e monogâmica (Foucault, 1988). Não obstante, ao longo dos anos, cada tentativa falha de estabelecer as causas da homossexualidade acabou por demonstrar que tampouco é possível estabelecer bases mensuráveis confiáveis para explicar tanto a homossexualidade quanto a heterossexualidade. Assim, se ser homossexual não encontra respostas na biologia, anatomia, ou nos hormônios, tampouco a heterossexualidade tem ali suas justificativas (Terry, 1995).

É inegável que somos herdeiros das assertivas e dos diagnósticos que se gestaram durante o final do século XIX e início do século XX, os quais codificaram o que Rose Braidotti chamou de "psicopatologia das paixões". De acordo com Braidotti (2002, p. 175):

... a seleção de objetos "apropriados" requer a eliminação de outros como inapropriados ou "abjetos". A distinção entre objetos de desejo apropriados e abjetos é fundamental para a psicanálise e se utiliza para vigiar as fronteiras entre o normal e o patológico, que é um dos pré-requisitos para conseguir entrar no comportamento civilizado e, portanto, na ordem social ${ }^{5}$ [tradução do autor].

Assim, naquele contexto, sob o pretexto de manter assegurada a ordem social se prescreveu a normalização da heterossexualidade. Historicamente, “. . . os últimos anos do século XIX, representam os primeiros anos da época hete-

No original: “...la selección de objetos 'apropiados' requiere la eliminación de otros como inapropiados o 'abyectos'. La distinción entre objetos de deseo apropiados y abyectos es fundamental para el psicoanálisis y se utiliza para vigilar las fronteras entre lo normal y lo patológico, que es uno de los prerrequisitos para conseguir entrar en el comportamiento civilizado y, por lo tanto, en el orden social." 
rossexual. Nesse período, os médicos da mente . . f formularam publicamente pela primeira vez a ideia de heterossexual e homossexual" (Katz, 1996, p. 43).

O paradigma científico dominante que considerou a homossexualidade enquanto doença viria a ser revisto quase um século depois, mais especificamente, em 1973, quando a American Psychiatric Association (APA) deixa de considerá-la nestes termos. E, apenas vinte anos depois a Organização Mundial de Saúde (OMS) virá a retirá-la de sua classificação internacional de doenças. É por isso que Jurandir Freire Costa (1992, p. 18) nos alerta para o fato de que ". . . a psicanálise não pode escapar das sombras da história".

Reconhecer que os sujeitos se constroem dentro de sistemas de significado e de representações culturais, os quais estão marcados por relações de poder, nos permite descortinar as estratégias teóricas e epistemológicas que foram empregadas para apreender os sujeitos no campo social. Mas também, é importante reconhecer que a emergência do conhecimento científico nunca foi desinteressada, pois “. . . a verdade não existe fora do poder ou sem poder . . (Foucault, 1979, p. 12). Para Foucault (1979, p. 12):

A verdade é deste mundo; ela é produzida nele graças a múltiplas coerções e nele produz efeitos regulamentados de poder. Cada sociedade tem seu regime de verdade, sua "política geral" de verdade: isto é, os tipos de discurso que ela acolhe e faz funcionar como verdadeiros; os mecanismos e as instâncias que permitem distinguir os enunciados verdadeiros dos falsos, a maneira como se sanciona uns e outros; as técnicas e os procedimentos que são valorizados para a obtenção da verdade; o estatuto daqueles que têm o encargo de dizer o que funciona como verdadeiro.

O modelo binário e dicotômico que regula o sexo e a sexualidade engendra a todos a partir do essencialismo biológico, como se todos fossem naturalmente inclinados para a heterossexualidade. Este raciocínio mascara a diversidade de arranjos sexuais que existe e reduz os pares sexuais entre aqueles que são heterossexuais ou seu oposto - homossexuais. Qualquer variante entre estas duas formas de desejo é assim desprezada, como por exemplo, a bissexualidade.

Aqueles que se orientam para a bissexualidade, por não fixarem a eleição de um parceiro sexual em apenas um polo do modelo binário e dicotômico, produzem uma instabilidade no sistema heteronormativo. De certa forma, o que a bissexualidade deixa entrever é o quanto a homossexualidade está a serviço da heterossexualidade obrigatória, já que ambas estão normativizadas dentro de uma construção cultural androcentricamente generificada.

Diante da homofobia, cada vez mais crescente, que tem assolado nossa sociedade é imprescindível que coloquemos em xeque os discursos binários de sexo, gênero e sexualidade que recomendam a manifestação do desejo, exclusivamente, nos termos da heterossexualidade.

Desde a emergência do sujeito heterossexual (imune às contingências históricas) todas aquelas pessoas, que não seguem as normativas da heterossexualidade, têm estado à mercê da homofobia. Instrumento da tecnologia biopolítica de dominação heterosocial, a homofobia trabalha como a grande guardiã das fronteiras bicaterorizadas de gênero e sexualidade.

Combater a homofobia implica confrontar a lógica hegemônica das categorias de gênero e de sexualidade do sistema heteronormativo, pois os discursos conjuram efeitos materiais e não apenas simbólicos. Para Monique Wittig (1992, p. 50): "Este poder que tem a ciência ou a teoria de atuar materialmente e efetivamente sobre nossos corpos e mentes não tem nada de abstrato, ainda que o discurso que produzem, certamente, seja $^{6}$ [tradução do autor]".

Particularmente, consideramos que os discursos que se pretendem subversivos ao regime binário de concepção heterocentrada têm que ser contingentes e desprovidos de pressupostos universais. Ao tomar o sujeito como contingente, novas linhas investigativas se abrem, possibili-

6 No original: "Este poder que tiene la ciencia o la teoría de actuar material y realmente sobre nuestros cuerpos y mentes no tiene nada de abstracto, aunque el discurso que produzcan sí lo sea". 
tando outras análises em torno daqueles que não se enquadram dentro do princípio de inteligibilidade da matriz heterossexual (Butler, 2003).

No entanto, trabalhar com discursos que se pretendam contingentes e desprovidos de pressupostos universais traz consigo implicações metodológicas difíceis de sanar no campo do conhecimento científico organizado em disciplinas.

Primeiro por que no processo de produção do conhecimento científico está supervalorizado o universal. Além disso, as teorias aludem a uma área de conhecimento, ou campo de saber, que está sob a guarda de especialistas que tacitamente se põem em acordo quanto a um conjunto de enunciados que pretendem compreender e explicar um determinado domínio da realidade. Questionar o saber instituído significa travar uma batalha pelo direito e o poder de significar, implica travar “. . . um combate 'pela verdade' ou, ao menos, 'em torno da verdade' ...", como diria Michel Foucault (1979, p. 13).

Historicamente, foram os ativistas gays e lésbicas norte-americanos que primeiro adotaram e utilizaram o termo queer como uma estratégia política de afirmação e autoidentificação no plano identitário. Assim, de mero insulto, queer vai se transformar em uma estratégia de representação que visava subverter a carga de homofobia subjacente ao termo. Deste modo, em seu inicio, as políticas queer se destacam como uma via de enfrentamento as lógicas identitárias das estruturas normativas do regime heterossexual em uma perspectiva política antes que científica.

Será a partir da década de 1990 que o campo de estudos da teoria feminista e dos estudos gays e lésbicos voltará seu olhar às problematizações lançadas pela política queer de enfrentamento a identidade como algo fixo e natural. No entanto, ao ser incorporado pelo meio acadêmico o termo queer perderá muito de sua potência subversiva já que dele será exigido uma definição precisa que corre o risco de cair no quadro normativo das categorizações ao qual sempre se opôs. Por isso, para não incorrer no erro de converter a teoria queer em uma nova ortodoxia preferimos trabalhar com a ideia de pensamento queer. Pois, como já alertou David Halperin (2007, p. 135):
"Em qualquer caso, quanto mais se tende a converter a teoria queer em uma disciplina acadêmica normativa, menos se poderá plausivelmente se pretender queer ${ }^{7}$ [tradução do autor]".

A heternormatividade, em sua potência coercitiva, demarca valorações e estabelece fronteiras que organizam um "nós" identitário. A identidade construída na tensão nós-eles produz diferentes formas de pertencimento e/ou exclusão que afetam os laços sociais e as inscrições subjetivas daqueles que integram ou ficam por fora desta "coletividade social". Para Trinh T. Minh-ha (1988), feminista que se insere no debate teórico e político da crítica pós-colonial: "Levantar a questão da identidade significa reabrir uma vez mais a discussão sobre a relação eu/outro na representação das relações de poder ${ }^{8}$ [tradução do autor]". Nesse sentido, não há nenhuma naturalidade na assunção de uma identidade, na verdade, as categorias identitárias são polos de adoutrinamento massivos que tratam de modelar as subjetividades em termos antinômicos. E tampouco se pode assegurar que as pessoas que se reconhecem sob uma mesma designação identitária percebam a si mesmas do mesmo modo, pois nada garante que existam duas experiências exatamente iguais no modo como os sujeitos se encarnam em uma mesma denominação identitária9 ${ }^{9}$.

No campo dos Estudos Culturais, Stuart Hall (2000, p. 109) compreende que as identidades:

. . . emergem no interior do jogo de modalidades específicas de poder e são, assim, mais o produto da marcação da diferença e da exclusão do que o signo de uma unidade idêntica, naturalmente constituída, de uma

7 No original: "En cualquier caso, cuanto más tienda a convertirse la teoría queer en una disciplina académica normativa, menos podrá plausiblemente pretenderse queer".

8 No original: "To raise the question of identity is to reopen again the discussion on the self/other relationship in the enactment of power relations".

9 Para maiores informações sobre a pluralidade na autopercepção identitária de gays e lésbicas no Movimento LGBT (Lésbicas, Gays, Bissexuais, Travestis, Transexuais e Transgêneros) brasileiro, consultar Pinafi (2012). 
"identidade" em seu significado tradicional

- isto é, uma mesmidade que tudo inclui,

uma identidade sem costuras, inteiriça, sem

diferenciação interna.

$\mathrm{Na}$ verdade, construir-se em determinada identidade, seja ela qual for, é um procedimento que passa por curtos-circuitos, extravios, medo e renuncias. De fato, não há nenhuma naturalidade no modo como as identidades capturam as pessoas; antes que um princípio autoevidente, o processo de produção de identidades se dá através da coerção e por meio da marcação da diferença e da exclusão. Nesse processo alguns serão melhores sujeitos que outros, terão mais direitos que outros, ou mais reconhecimento social. Isto porque, como diz Tomaz Tadeu da Silva (2000, p. 81): "A identidade e a diferença estão, pois, em estreita conexão com relações de poder. $\mathrm{O}$ poder de definir a identidade e de marcar a diferença não pode ser separado das relações mais amplas de poder".

A teia insidiosa que nos prende a identidades estanques é problematizada pelo pensamento queer, o qual busca desmantelar o caráter autoevidente da identidade. Para Annamarie Jagose (1996, p. 130): “A proliferação discursiva do queer foi habilitada em parte pelo conhecimento de que as identidades são fictícias - produzidas por e produtoras de efeitos materiais e, entretanto, arbitrárias, contingentes e motivadas ideologicamente [tradução do autor]" ${ }^{10}$. Por isso, queer não deveria ser tomado como uma categoria identitária, mas sim como uma crítica as categorias identitárias. Nesse sentido, "Queer é sempre uma identidade sob construção, um lugar em construção permanente . . [ [tradução do autor]"11 (Jagose, 1996, p. 131).

Ao opor-se aos efeitos totalizadores da identidade, o pensamento queer se apresenta como uma forma de identificação política que bus-

10 No original: "The discursive proliferation of queer has been enabled in part by the knowledge that identities are fictitious - that is, produced by and productive of material effects but nevertheless arbitrary, contingent and ideologically motivated".

11 No original: "Queer is always an identity under construction, a site of permanent becoming ...". ca problematizar as premissas epistemológicas prioritárias daqueles que reclamam para si determinado tipo de identidade, questionando a política da diferença sexual e os imperativos de gênero e sexualidade. Desse modo, o queer evoca a diferença, mas sem o objetivo de integrá-la, assimilá-la ou de que seja tolerada; ele é a diferença que objetiva incomodar o status quo e, de forma adjacente, o discurso queer irá buscar expandir a noção de identidade para além das oposições dialéticas. Para Beatriz Preciado (2003): “O que está em jogo [na política queer] é como resistir ou como reconverter as formas de subjetivação sexopolíticas. Esta reapropriação dos discursos de produção de poder/saber sobre o sexo é um abalo epistemológico ${ }^{12}$ [tradução do autor]".

Ao avivar os debates em torno à pressuposta estabilidade do gênero, da sexualidade, do corpo e da subjetividade; o pensamento queer tem expandido a palheta de cores disponível para a confecção de autorretratos, alguns deles, disruptivos. De acordo com David Halperin (2007, p. 88): "Ao resistir às práticas discursivas e institucionais . . . as identidades queer podem abrir um espaço social para a construção de identidades diferentes, a elaboração de vários tipos de relações e o desenvolvimento de novas formas culturais ${ }^{13}$ [tradução do autor]".

$\mathrm{Na}$ contemporaneidade, frente à ampla pluralidade dos arranjos sexuais e de gênero (seja pela cada vez menor prevalência da família nuclear, seja pela diversidade dos casais de gays e lésbicas, ou pelas pessoas adeptas ao cross-dresser, dentre outros casos), é ilusório julgar que o pensamento binário seja capaz de apreender as existências humanas em toda sua complexidade, com todas suas idiossincrasias. Isto porque, seu

12 No original: "Lo que está en juego [na política queer] es cómo resistir o cómo reconvertir las formas de subjetivación sexopolíticas. Esta reapropiación de los discursos de producción de poder/saber sobre el sexo es una conmoción epistemológica".

13 No original: “Al resistir a las prácticas discursivas e institucionales . . las identidades queers pueden abrir un espacio social para la construcción de identidades diferentes, la elaboración de varios tipos de relaciones y el desarrollo de nuevas formas culturales". 
campo interpretativo é muito limitado à medida que se restringe a compreensões estanques, sem matizes, comprimindo toda pluralidade nos modelos interpretativos já consolidados. Contudo, se nos propusermos a analisar as sexualidades e as relações de gênero não mais em relação à postura essencialista, poderemos tecer reflexões acerca das novas expressões sexuais e de gêneros (drag queens, cross-dresser, travestis, transgêneros, ou seja, bodies that matter ${ }^{14}$ ) em base às histórias de vida daqueles que vivem fora das fronteiras da matriz heterossexual. De fato, o modelo epistemológico erigido sob um sujeito dado de antemão nas ciências humanas veio a se constituir em uma das formas de legitimação da discriminação sexo/gênero. E, “. . . compreender a ciência como cultura e na cultura é uma primeira premissa, ou um dado de qualquer análise inteligente do conhecimento científico ${ }^{15}$ [tradução do autor]" (Terry, 1995, p. 135).

Agora, como antes, a psicologia não pode ser refratária aos acontecimentos sociais, devendo considerar os sujeitos não apenas em face de sua interioridade como também perante as relações sociais, históricas e culturais do ambiente que os circunda. Para Drescher, D'Ercole e Schoenberg (2003, p. 2):

Como clínicos, podemos nos ver presos em um espaço entre perspectivas essencialistas e pós-modernas. Contudo, já não podemos nos refugiar em teorias psicodinâmicas que excluem preocupações sociais, culturais, e, conflitos. Hoje em dia, valores pessoais, opiniões, e, atitudes, junto com os modelos dentro dos quais um terapeuta é treinado, são reconhecidos como parte do processo terapêutico. Além disso, os clínicos reconheceram que nem todos os terapeutas pen-

14 Bodies that matter faz referência a obra de Butler (1998). O título é um trocadilho com a palavra "matter", que pode adquirir o sentido tanto de peso (no sentido de materialidade) quanto de importância/legitimidade. Para uma explicação pormenorizada sobre a inteligibilidade de certos tipos de corpos, ver entrevista: Butler (2002).

15 No original: “. . . understanding science as culture and in culture is a first premise, or a given of any intelligent analysis of scientific knowledge". sam do mesmo modo. De fato, estas diferenças são bem-vindas à medida que oferecem uma experiência que tem potencial de significado e valor ${ }^{16}$ [tradução do autor].

Enquanto profissionais responsáveis pela construção de saberes sobre os sujeitos devemos nos engajar na busca de formulações teóricas que coloquem em tela a naturalidade com que marcamos certas existências como abjetas para, assim, incitar um pensamento de combate à homofobia prevalecente em nossa sociedade.

É indispensável que a psicologia volte seu olhar para as problematizações que o pensamento queer faz à estruturação do modelo antitético (normal x abjeto), o qual é ordenador de uma tecnologia política de produção de indivíduos, para, assim, produzir conhecimentos que expandam tanto os binarismos anatômicos e de gênero, quanto os da heteronormatividade. Na verdade, enquanto o pensamento normal versus abjeto seguir como princípio organizador das fronteiras que distinguem as identidades sexuais e de gênero, muito dificilmente o binário interdepentende heterossexismo-homofobia deixará de vigorar em nossa sociedade.

É de fundamental importância que trabalhemos para o desenvolvimento de conhecimentos que ajudem a desestabilizar o paradigma binário de concepção heterocentrada do humano, pois demasiadas vidas são destroçadas pela homofobia todos os dias devido à inaptidão para suportar a diferença. A identidade estruturada por sistemas de pensamento duros, que classificam os indivíduos em categorias estanques, arma totalidades que mais facilmente deslizam para a discriminação. E, nesse ponto, queer pode

16 No original: "As clinicians, we may find ourselves lodged in a space between essentialist and postmodern perspectives. Nevertheless, we can no longer take refuge in psychodynamic theories that exclude social concerns, cultures, and conflicts. Today, personal values, opinions, and attitudes, along with the models in which a therapist is trained, are all acknowledged as part of the therapeutic process. Furthermore, clinicians acknowledged that all therapists do not think alike. In fact, these differences are welcomed as each offers a piece of experience that has potential meaning and value." 
funcionar como um novo marco discursivo para falar sobre os sexos, gêneros, desejos e sexualidade, ao promover a instabilidade das categorias identitárias.

\section{Referências}

Braidotti, R. (2002). Metamorfosis. Hacia una teoría materialista del devenir. Madrid, España: Akal.

Butler, J. (1998). Boddies that Matter: On the discursive limits of sex. New York: Routledge.

Butler, J. (2002). Como os corpos se tornam matéria: Entrevista com Judith Butler. Revista Estudos Feministas (Florianópolis), 10(1), 155-167. doi:10.1590/S0104-026X2002000100009

Butler, J. (2003). Problemas de gênero: Feminismo e subversão da identidade. Rio de Janeiro, RJ: Civilização Brasileira.

Costa, J. F. (1992). A inocência e o vício: Estudos sobre o homoerotismo. Rio de Janeiro, RJ: Relume-Dumará.

Drescher, J., D’Ercole, A., \& Schoenberg, E. (Eds.). (2003). Psychotherapy with gay men and lesbian: Contemporary dynamic approaches. New York: The Haworth Press.

Foucault, M. (1979). Microfísica do poder (2. ed.). Rio de Janeiro, RJ: Graal.

Foucault, M. (1988). História da sexualidade I: A vontade de saber (16. ed.). Rio de Janeiro, RJ: Graal.

Foucault, M. (2008). Segurança, território, população. São Paulo, SP: Martins Fontes.

Hall, S. (2000). Quem precisa da identidade? In T. T. Silva, S. Hall, \& K. Woodward (Eds.), Identidade e diferença: A perspectiva dos Estudos Culturais (pp. 103-133). Petropólis, RJ: Vozes.

Halperin, D. (2007). San Foucault. Para una hagiografía gay. Buenos Aires, Argentina: El Cuenco de Plata.

Jagose, A. (1996). Queer Theory: An introduction. New York: Melbourne University Press.
Katz, J. N. (1996). A invenção da heterossexualidade. Rio de Janeiro, RJ: Ediouro.

Minayo, M. C. S. (2001). Ciência, técnica e arte: O desafio da pesquisa social. In S. F. Deslandes (Ed.), Pesquisa social: Teoria, método e criatividade (18. ed., pp. 9-29). Petrópolis, RJ: Vozes.

Minh-Ha, T. T. (1988). Not you-like you: Post-colonial women and the interlocking questions of identity and difference. In D. Gordon, G. Batchen, J. Clifford, V. Diaz, J. Hawkins, V. Kirby, ...M. Sturken (Ed.), Feminism and the critique of colonial discourse: Inscriptions 3-4. Santa Cruz, CA: Center for Cultural Studies. Retrieved from http://culturalstudies.ucsc.edu/PUBS/Inscriptions/vol_3-4/minh-ha.html

Pinafi, T. (2012). Homofobia na militância de gays e lésbicas do Brasil. Rio de Janeiro, RJ: Multifoco.

Preciado, B. (2003). Multitudes queer: notas para una política de los "anormales". Revista Multitudes (Paris), 12. Recuperado em http://www.hartza. com/anormales.htm

Silva, T. T. (2000). A produção social da identidade e da diferença. In T. T. Silva, S. Hall, \& K. Woodward (Eds.), Identidade e diferença: A perspectiva dos Estudos Culturais (pp. 73-102). Petropólis, RJ: Vozes.

Terry, J. (1995). The seductive power of science in the making of deviant subjectivity. In J. Halberstam \& I. Livingston (Eds.), Posthuman bodies (pp. 135-161). Bloomington, IN: Indiana University Press.

Wittig, M. (1992). El pensamiento heterosexual. In M. Wittig, El pensamiento heterosexual y otros ensayos (pp. 45-58). Madrid, España: Egales.

Recebido: 26/03/2013

$1^{a}$ revisão: $14 / 07 / 2014$ Aceite final: 10/09/2014 